University of Nebraska - Lincoln

DigitalCommons@University of Nebraska - Lincoln

Faculty Publications: Department of Entomology

Entomology, Department of

$3-21-2006$

\title{
Movement of Cicindela hirticollis Say Larvae in Response to Moisture and Flooding
}

\author{
Mathew L. Brust \\ University of Nebraska-Lincoln, mbrust@csc.edu \\ William Wyatt Hoback \\ University of Nebraska at Kearney, whoback@okstate.edu \\ Kerri Farnsworth Skinner \\ University of Nebraska at Kearney, kefarns@okstate.edu \\ Charles Barry Knisley \\ Randolph-Macon College
}

Follow this and additional works at: https://digitalcommons.unl.edu/entomologyfacpub

Part of the Entomology Commons

Brust, Mathew L.; Hoback, William Wyatt; Skinner, Kerri Farnsworth; and Knisley, Charles Barry, "Movement of Cicindela hirticollis Say Larvae in Response to Moisture and Flooding" (2006). Faculty Publications: Department of Entomology. 80.

https://digitalcommons.unl.edu/entomologyfacpub/80

This Article is brought to you for free and open access by the Entomology, Department of at DigitalCommons@University of Nebraska - Lincoln. It has been accepted for inclusion in Faculty Publications: Department of Entomology by an authorized administrator of DigitalCommons@University of Nebraska - Lincoln. 
Published in Journal of Insect Behavior 19:2 (March 2006), pp. 251-263;

doi 10.1007/s10905-006-9021-8 http://springerlink.metapress.com/content/104914/

Copyright (C) 2006 Springer Science+Business Media, Inc. Used by permission.

Revised October 28, 2005; accepted January 10, 2006; published online June 17, 2006

\title{
Movement of Cicindela hirticollis Say Larvae in Response to Moisture and Flooding
}

\author{
Mathew Louis Brust ${ }^{1}$, William Wyatt Hoback ${ }^{1}$, \\ Kerri Farnsworth Skinner ${ }^{1}$, and Charles Barry Knisley ${ }^{2}$
}

${ }^{1}$ Department of Biology, Bruner Hall of Science, University of Nebraska at Kearney, 905 W. 25th Street, Kearney, Nebraska 68849, USA

${ }^{2}$ Department of Biology, Randolph-Macon College, Ashland, Virginia 23005, USA Corresponding author: William Wyatt Hoback, email hobackww@unk.edu

\begin{abstract}
The larvae of the tiger beetle, Cicindela hirticollis Say, inhabit sandy shoreline areas that flood periodically. This species has declined over much of its range and at least one subspecies is near extinction, possibly as a result of human alteration of waterways. In addition to physiological tolerance for anoxia, the larvae have physical and behavioral adaptations to avoid drowning. We hypothesized that $C$. hirticollis larvae would exhibit behavioral responses to soil moisture change and flooding because, unlike most other tiger beetles, they frequently relocate their burrows. Our laboratory studies demonstrated that larvae select surface soil moisture levels of $7-50 \%$ saturation in which to dig new burrows. Within $96 \mathrm{~h}$ of immersion, most larvae abandon burrows and larvae do not form new burrows in darkness. Larvae may relocate when flooded, suggesting a previously undocumented mechanism for dispersal; however, dams often eliminate suitable habitat areas downstream, suggesting that this behavior may be detrimental in riverine populations. Because larvae move during daylight hours, they also are likely to suffer mortality from trampling due to human recreational activity.
\end{abstract}

Keywords: tiger beetle, flooding, behavior, conservation 


\section{Introduction}

The larval stages of most tiger beetle species are soil-dwelling, long-lived, and sedentary (Knisley and Hill, 1992; Pearson and Vogler, 2001). Females are specific in choosing oviposition sites (Knisley and Schultz, 1997; Hoback et al., 2000a,b), and the larvae of most species spend their entire life in the same location, enlarging the diameter and depth of the burrow with each of three successive instars (Knisley and Pearson, 1984; Knisley and Schultz 1997; Pearson and Vogler, 2001). Habitats used by tiger beetles in the temperate zones typically have areas that are sparsely vegetated or devoid of vegetation. Such habitats include stream and pond edges, dunes and blowouts, seashores, salt flats, and open areas in grasslands (Pearson, 1988; Larochelle and Lariviere, 2001). Larvae often co-occur with adults (Knisley and Schultz, 1997), but in some cases the two life-stages occur in different microhabitats (Knisley and Pearson, 1984).

Because they are adapted to specific environments, many tiger beetle species are sensitive to habitat changes and may be especially vulnerable to the effects of hydrologic change or excessive disturbance. Several water-edge tiger beetle species have experienced sharp declines in both abundance and distribution over the past century (Nagano, 1980; Shook, 1981; Knisley and Schultz, 1997; Larochelle and Lariviere, 2001). The most geographically widespread of these declining species is Cicindela hirticollis Say (Larochelle and Lariviere, 2001).

Cicindela hirticollis occurs across much of North America with populations found along rivers, large lakes, and seashores from Florida to California north to Labrador, the southern edge of Nunavut, and British Columbia. Despite its broad range, it is apparently lacking from the Great Basin and much of the Appalachian region. The regions where $C$. hirticollis does not occur either lack permanent streams or the streams tend to be of high gradient and lack the soft sandy substrates utilized by this species (Graves et al., 1988).

Of the eleven subspecies of $C$. hirticollis currently recognized, at least three have decreased dramatically in the last 30 years (Nagano, 1980; Dunn, 1981; Graves et al., 1988; Larochelle and Lariviere, 2001; Knisley, 2003). Human-induced changes, including hydrologic alterations, dams, and compaction from human activity, are believed to be the primary cause of the decline. Beach trampling was apparently responsible for the decline of two subspecies (Nagano, 1980; Dunn, 1981). Cicindela hirticollis gravida LeConte is extinct over most of its former range in the southern half of California (Nagano, 1980). Cicindela hirticollis rhodensis Calder is threatened in much of its former range in New England (Dunn, 1981; Larochelle and Lariviere, 2001) and has disappeared from many historic sites near the Great Lakes. This beetle has been eliminated from heavily used state parks on the western shoreline of Lake Michigan (M. L. Brust, unpublished).

Unlike most other tiger beetle species, the larvae of Cicindela hirticollis relocate their burrows and are often observed crawling on the sand surface (Shelford, 1908; Knisley and Schultz, 1997). Although the reasons for this movement are not clearly understood, Shelford (1908) found that C. hirticollis larvae would abandon old burrows and dig new ones in response to slight changes in soil moisture. Disturbance of habitat can change moisture gradients within the soil, leading to larval desiccation, and may trigger relocation (Wilson, 1970; Stamatov, 1972; Nagano, 1980; Schultz, 1988; Knisley and Hill, 1992). Shelford (1908) found that movement exposed larvae to mortality from diurnal predators. Although larvae are often observed moving during the day (Knisley and Schultz, 1997), we suspect that larvae also relocate at night, when risks of predation and desiccation are lower.

Our recent studies have demonstrated $C$. hirticollis larvae have poor immersion tolerance (Brust et al., 2005). We hypothesized that larvae may exhibit behavioral responses that increase survival in frequently flooded water edge habitats. To test this and to determine if larvae use moisture cues to select new burrow locations, we conducted laboratory experiments and made field observations of larval habitat. We also determined whether flooded larvae move in light and darkness.

\section{Materials and Methods}

\section{Organisms for Laboratory Tests}

Our laboratory experiments used larvae of Cicindela hirticollis hirticollis Say that were collected along the Chesapeake Bay, from Northampton County, Virginia, $6 \mathrm{~km}$ NNE of Reedville. This subspecies was chosen because larvae are abundant and widespread, occurring both on the coast and along eastern rivers and lakes. Information in the literature (Graves et al., 1988) and our experience indicates that all subspecies of $C$. hirticollis are similar in biology and behavior. Larvae were collected in July, August, and September of 2003 by waiting for larvae to appear at the top of the burrow and then using a trowel to block larval retreat.

\section{Selection of Burrow Location}

To quantify larval selection of habitats with different soil moistures, three arrays of four 13.2-L aquaria (3.5 gallon) were connected along two of their 


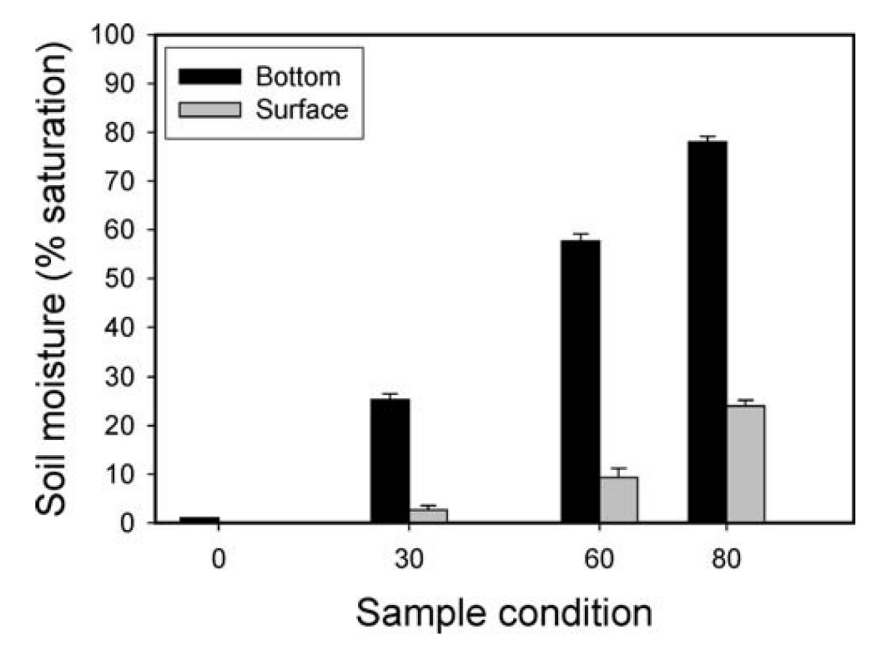

Figure 1. Mean ( \pm standard error) soil moisture (\%) at the bottom and surface of experimental arrays used to test larval burrow selection.

sides with duct-tape. A plastic barrier was secured around the top of each array to prevent escape by larvae. Each aquarium was filled with sand until the sand was flush with the top. As each was filled, an Aquapro ${ }^{\mathrm{TM}}$ sample tube was placed in the center of the aquarium so that soil moisture could be measured throughout the soil column. With the soil moisture probe in the tube, water was added until one of four pre-assigned moisture levels (o, 30, 60, and $80 \%$ saturation) was achieved at the bottom. Soil moisture was recorded at the bottom and top of each aquarium (Figure 1). The arrays were then allowed to stabilize for 1 day and moisture levels were re-measured before larvae were introduced. The arrays were kept in the laboratory at room temperature (measured at $21.5^{\circ} \mathrm{C}$ ).

Individual third instars were placed on an 8 by $8 \mathrm{~cm}$ card in the middle of the array (overlapping the edge of all four aquaria). The procedure was repeated after each larva left the note card until 12 larvae were released in each array. The larvae were allowed $24 \mathrm{~h}$ to dig a burrow in their desired location, and the number selecting each moisture level was recorded.

\section{Larval Response to Flooding}

To test larval responses to flooding, water was first added to the dry (o\%) aquarium in each array to produce $60 \%$ soil moisture. After waiting $24 \mathrm{~h}$ to test for larval dispersal from existing burrows (as control), the 60 and $80 \%$ soil moisture aquaria containing C. hirticollis larvae were flooded to $100 \%$ saturation (standing water). Larvae that emerged from flooded burrows could then choose between the original 30\% saturated aquarium or the new $60 \%$ saturated aquarium, and we recorded new burrow locations after 24, 48, and $72 \mathrm{~h}$. Data were analyzed with analysis of variance followed by a Bonferroni test to separate means.

In a second test, sand was added to $7 \cdot 5$-L ( 2 gallon) plastic containers $(32.5 \mathrm{~cm}$ long $\times 20.3 \mathrm{~cm}$ wide $\times 20.3 \mathrm{~cm}$ high) to simulate a sloped beach, with depths from $2.5 \mathrm{~cm}$ at one end to $20 \mathrm{~cm}$ at the other end. The sand was then thoroughly wetted. Four third instars were placed individually on the sand in a row across a line where it was $15 \mathrm{~cm}$ deep and covered with a vial until they dug a burrow. The test was replicated ten times, and chambers were kept in the laboratory at room temperature. For each replicate, a new set of four larvae was used. After 5 days of acclimation to burrows and one to two feedings, the trial was begun by adding brackish water from the Chesapeake Bay to cover the sand in the chambers on the following schedule: one-third of sand covered at $0800 \mathrm{~h}$; two-thirds of sand covered at $1000 \mathrm{~h}$; and sand completely covered at $1200 \mathrm{~h}$. After the sand was completely covered, larval activity was recorded at 12, 24, 36, 48, 60, 72, and $96 \mathrm{~h}$. Visible larvae were recorded as out of the burrow and then categorized as floating, sunk, or dead.

\section{Effect of Light on Post-Flooding Larval Activity}

The effects of light on movement and burrowing behavior were tested by connecting two 1.25-L plastic containers side by side with duct tape and creating a barrier around the two connected containers by folding the duct tape over itself. The area connecting the two containers was left without a barrier. Four of these two-container arrays were created. Sand was added to each container until it was flush with the top. In each array, one container was left dry, while water was added to the other to approximately 50\% soil moisture. The containers were allowed to stabilize for $24 \mathrm{~h}$. After $24 \mathrm{~h}$, a cardboard barrier was inserted between the two connected containers. Six third instars were then released one by one into the moist container. Approximately 5 min were allowed between releases to minimize cannibalism and no more than four larvae were allowed to be searching for a larval burrow location at one time.

Once all larvae had established burrows, the cardboard barrier was removed and water was added to the previously dry container until soil moisture reached approximately 50\%. Two arrays were placed in a lighted envi- 
ronmental chamber at $16.5^{\circ} \mathrm{C}$ and two were placed in a dark environmental chamber at $16.5^{\circ} \mathrm{C}$. The room containing the unlighted environmental chamber was also unlit. In each replication, the orientation of the two arrays was opposite and both were placed along the same wall of the environmental chamber to reduce potential uncontrolled variables. The arrays were checked after $24 \mathrm{~h}$ to ensure that no larval movement had occurred prior to flooding of established burrows. The container with established larvae was then flooded until standing water was present, and the arrays were placed back in the environmental chambers in their original orientation. The arrays were checked at 2, 4, 6, 8 10, 20, 26, and $30 \mathrm{~h}$ for movement of larvae and establishment of new larval burrows in the container that was not flooded.

\section{Results}

\section{Selection of Burrow Location}

In the experiment to test habitat selection based on soil moisture, 28 of 36 larvae dug burrows. The remaining larvae were cannibalized or apparently drowned. The majority of larvae were observed circling the treatment arrays numerous times before choosing a site, and thus most larvae experienced every test condition. Compared to moister conditions, larvae avoided the $0 \%$ (dry) and 30\% soil moisture conditions (ANOVA, $P<0.05$ ). Approximately equal numbers of larvae established burrows in the $60 \%$ soil moisture $(N=13)$, and $80 \%$ soil moisture $(N=15)$ conditions and there were no significant differences $(P=0.67)$. Larvae presumably chose burrow locations based on surface moisture content, which related to subsurface moisture (Figure 1) As they sought locations to dig burrows, larvae encountered all conditions; however, no larva probed the surface or attempted to dig a burrow in the $0 \%$ or $30 \%$ treatments. When the dry condition (o\% soil moisture) was increased to $60 \%$ soil moisture, none of the larvae in the other conditions moved during the 24-h observation period prior to immersion of established burrows.

\section{Larval Response to Flooding}

Upon flooding, larvae (24 of 28) moved to the new 60\% saturated treatment. Four larvae drowned and were recovered after the experiment. All surviving larvae established new burrows within $72 \mathrm{~h}$. In the second test, which simulated flooded beach conditions, larvae gradually left flooded burrows. Within 12 h, 25\% had left flooded burrows, and all had emerged within $96 \mathrm{~h}$

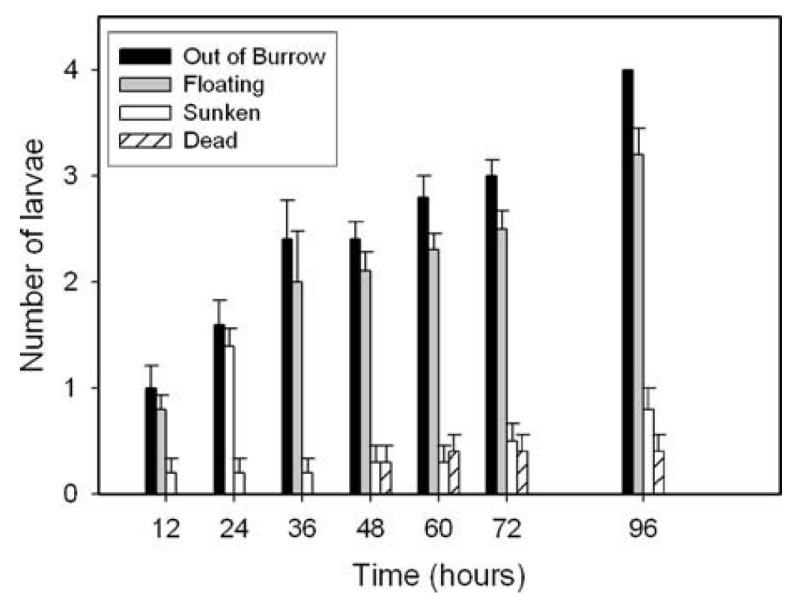

Figure 2. Activity of third instars under simulated flooded beach conditions. Bars represent mean ( \pm standard error) number of larvae exhibiting each activity (10 replicates).

(Figure 2). Because no dry habitat was available in the chambers, larvae could not escape, and floating larvae gradually sank. Approximately $12 \%$ of these larvae were dead after $96 \mathrm{~h}$.

\section{Effect of Light on Post-Flooding Larval Activity}

No movement occurred during the 24-h period prior to flooding of the established burrows in the two-container arrays. Thirty hours post-flooding, 9 of 12 larvae under lighted conditions left the flooded container and established new burrows, whereas none of the larvae under dark conditions dug burrows. During the first three observation periods, larvae under dark conditions were noted crawling on the sand of the 50\% moisture condition, but at later times all visible larvae were floating in the flooded containers. Under lighted conditions, all larvae observed crawling on the moist sand had established new burrows within $10 \mathrm{~h}$ (Figure 3).

\section{Discussion}

The females of most tiger beetle species are specific in choosing oviposition sites (Hoback et al., 2000a,b), and larvae of most other species spend their entire larval development at this site (Knisley and Pearson, 1984; Pear- 

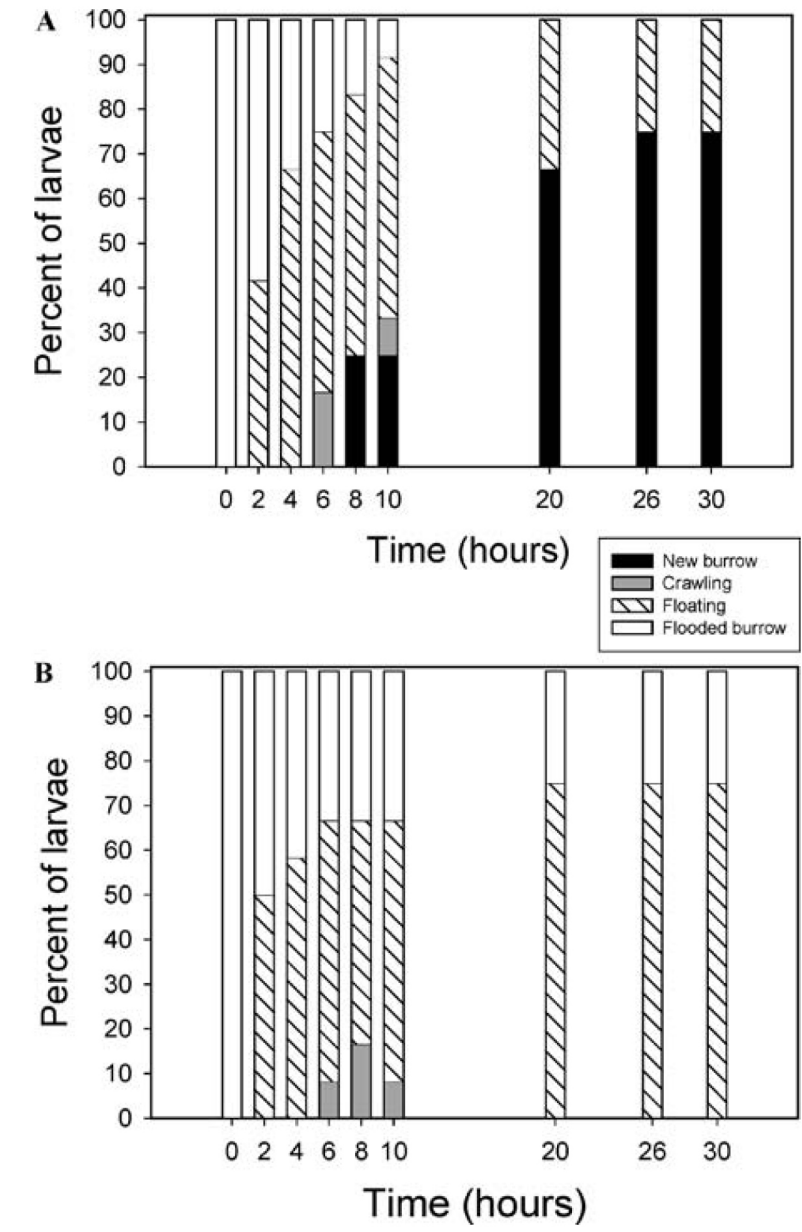

Figure 3. Response of larvae to flooding in light (A) and dark (B) conditions. Bars represent percent of total larvae $(N=12$ per condition; 2 replicates).

son and Vogler, 2001). While the adult female $C$. hirticollis selects the initial larval habitat by her selection of an oviposition site, the larvae move in response to drying (Shelford, 1980), immersion, or other factors. This study suggests that third instar $C$. hirticollis can also select burrow location based on soil moisture. Larvae did not establish new burrows in the dark; however, we observed larvae crawling on the moist sand in the dark during the experiment, which indicated that they initially escaped immersion (Figure 3). These results suggest that the larvae cannot determine their location in relation to surface water under dark conditions. As this experiment was conducted in small containers, the larvae were unable to crawl in a single direction for any significant distance, whereas under natural conditions it might be possible for larvae to move in one direction, perhaps using a surface gradient to select a burrow location and avoid standing water. It is likely that populations of $C$. hirticollis vary in movement depending on the stability of the local environment. For example, field observations of Cicindela hirticollis gravida during a 36-h period at Limantour Point in Point Reyes National Seashore, Marin County, California, found no larval movement among 83 marked larval burrows (Brust, 2004). However, the larvae at this site occur in a protected area and despite unusually high tides during the observation period, larvae were not flooded. Moreover, the depths to the water table remained fairly constant (Brust, 2004) and were nearly identical to those found by Wilson (1967) for burrows along Lake Michigan ranging between 20 and $30 \mathrm{~cm}$ below the soil surface. The specificity in selecting these locations suggests that larvae require a narrow range of soil moisture.

Presumably, the population of $C$. hirticollis at Point Reyes is likely to relocate burrows only during stormy spring conditions which produce local flooding. Larvae from other populations, in sites where water levels fluctuate, are frequently seen changing burrow locations. At shoreline sites along the Chesapeake Bay, which have less protected habitat than at Point Reyes, C. hirticollis larvae are frequently seen crawling on the sand surface, often moving toward the back beach (Knisley and Schultz, 1997). Brust (pers. obs.) has also collected $C$. hirticollis larvae while pitfall trapping in the general vicinity of larval burrows along the Platte River in Nebraska.

Our studies suggest that larvae select burrow locations that have at least $30 \%$ soil moisture (7\% surface moisture [Figure 1]). The reason larvae select wetter surface soils is unknown but it may be to avoid difficulties associated with digging in loose, dry sand. To form a burrow slightly larger than the pronotal diameter, some soil moisture is necessary for cohesion of soil particles and to prevent collapse of the burrow walls. Moreover, dry sand may abrade soft-bodied larvae, which could lead to desiccation.

During the trials in which water was added to top of the soil, all burrows collapsed when flooded and most larvae wriggled through the sand and floated to the water surface. In trials where non-flooded substrate was available, larvae managed to reach drier sand by bending and flipping their bodies until they reached the edge of the flooded sand. In natural riverine situations, larvae that leave burrows would be carried to a new location downstream. Thus, under natural conditions, flooding may serve as a dispersal mecha- 
nism for larvae of $C$. hirticollis by transporting them downstream in rivers or downwind in lake settings. This mode of dispersal has not been previously proposed for tiger beetle larvae, and it has long been assumed that tiger beetle dispersal occurred only during the adult stage (Pearson and Vogler, 2001).

In unaltered river systems in which sandbars move and new suitable habitat becomes exposed on a regular basis, such a mode of larval dispersal might be beneficial. If flooding moves larvae downstream, then adult $C$. hirticollis may fly upstream during dispersal flights. Such upstream dispersal of aquatic macroinvertebrates has long been known (Roos, 1957; Hershey et al., 1993; Williams and Williams, 1993).

Most large rivers have been altered by dams and flooding regimes have changed, often leading to prolonged periods of high and low water in downstream areas. This results in the encroachment and succession of vegetation to the high water mark (Baxter, 1977; Knisley, 2003) and reduces the amount of suitable habitat available to water-edge tiger beetle species. Dispersal during flooding events may cause larval mortality where anthropogenic changes to rivers have eliminated appropriate habitat. In such a situation, most larvae that wriggle free of the burrow and wash downstream probably die as a result of predation or desiccation while searching for suitable habitat. As a result, populations in such areas would likely decline with each flooding episode.

Thus, dispersal behavior may have contributed to the decline of C. hirticollis abrupta in the Sacramento River system in California. This subspecies once occurred in five limited areas within approximately $8,000 \mathrm{~km}^{2}$ on the Sacramento and Feather Rivers in central California (Knisley and Schultz, 1997), and its recent dramatic decline in distribution and abundance is believed to be the result of habitat changes associated with the Oroville and Shasta Dams (Knisley, 2003). This subspecies has not been found since 1984 (Knisley, pers. obs.). Dams are also believed to have caused the decline of Cicindela columbica Hatch in the Pacific Northwest (Beer, 1971; Shook, 1981), although the behavioral responses to flooding in this species are unknown.

The simulated flooded beach conditions yielded similar results to the soil moisture experiment. Both experiments resulted in some larval death after prolonged exposure to immersion. This suggests that larvae respond to flooding by escaping flooded areas, perhaps to compensate for low immersion survival (Brust et al., 2005). Other species which inhabit salt flats exposed to static water (Hoback et al., 1998) survive immersion in hypoxic water by switching to anaerobic metabolism (Hoback et al., 2000a). Tropical species which inhabit the Amazon River basin exhibit alternative adaptations to survive long periods of immersion including aquatic respiration, extreme tolerance of anoxia, and rapid development to the adult stage (Zerm and Adis, 2002; Zerm and Adis; 2004; Zerm et al., 2004). It is likely that the Amazonian species cannot use similar behavioral strategies as $C$. hirticollis because of the magnitude of water level changes associated with the Amazon River, the length of the rainy season, and the duration of flooding (exceeding 6 months in some areas).

Other tiger beetle species, such as $C$. repanda, occur in similar habitats in North America but have not experienced the severe population declines recorded for $C$. hirticollis. Its unusually frequent larval movement in response to desiccation and immersion may make $C$. hirticollis particularly vulnerable to habitat changes. Such behavior seems to risk predation and desiccation, particularly during daylight hours, and our behavioral studies indicate that larvae require light for burrow re-establishment (Figure 3). While nocturnal movement might result in long-term exposure to nocturnal predators, daytime movement could expose $C$. hirticollis to greater risk of trampling on beaches used by humans, as recreational activities are more likely to occur during daylight hours. Thus, this species could be especially susceptible to human impacts through flooding on altered rivers and recreational use of shoreline beaches.

\section{Acknowledgments}

We thank Dawn Adams for assistance in arranging for a research permit for the work at Point Reyes National Seashore related to this study. We gratefully acknowledge the assistance of Chris Nagano of the U.S. Fish and Wildlife Service, Sacramento Field Office, for his interest, support and facilitation of financial support for this work (USFWS contracts 10181-3-M374 and 10181333-M375). The University of Nebraska at Kearney Department of Biology and University of Nebraska Research Services Council also provided support for this work. This is Department Contribution \# 1245 and Journal \# 15093 of the University of Nebraska.

\section{References}

Baxter, R. M. (1977). Environmental effects of dams and impoundments. Annu. Rev. Ecol. Syst. 8: 255-283.

Beer, F. (1971). Note on Cicindela columbica Hatch. Cicindela 3: 32.

Brust, M. L. (2004). Distribution and Conservation Status of Nebraska Tiger Beetles and a Test of Immersion Tolerance by Cicindela hirticollis Say, Masters Thesis, University of Nebraska at Kearney, Kearney, NE, 170 pp. 
Brust, M. L., Hoback, W. W., Skinner, K. M., and Knisley, C. B. (2005). Differential immersion survival by populations of Cicindela hirticollis Say (Coleoptera: Cicindelidae). Ann. Entomol. Soc. Am. 98: 973-979.

Dunn, G. A. (1981). Tiger beetles of New Hampshire. Cicindela 13: 1-28.

Graves, R. C., Krejci, M. E., and Graves, C. F. (1988). Geographic variation in the North American tiger beetle, Cicindela hirticollis Say, with a description of five new subspecies (Coleoptera: Cicindelidae). The Can. Entomol. 120: 647-678.

Hershey, A. E., Pastor, J., Peterson, B. J., and Kling, G. W. (1993). Stable isotopes resolve the drift paradox for Baetis mayflies in an arctic river. Ecology 74: 2315-2325.

Hoback, W. W., Golick, D. A., Svatos, T. M., Spomer, S. M., and Higley, L. G. (200oa). Salinity and shade preferences result in ovipositional differences between sympatric tiger beetle species. Ecol. Entomol. 25: 180-187.

Hoback, W. W., Podrabsky, J. E., Higley, L. G., Stanley, D. W., and Hand, S. C. (200ob). Anoxia tolerance of con-familial tiger beetle larvae is associated with differences in energy flow and anaerobiosis. J. Comp. Physiol. B 170: 307-314.

Hoback, W. W., Stanley, D. W., Higley, L. G., and Barnhart, C. M. (1998). Survival of immersion and anoxia by larval tiger beetles, Cicindela togata. Am. Midland Nat. 140: $27-33$.

Knisley, C. B. (2003). A status review of the sacramento valley tiger beetle, Cicindela hirticollis abrupta, Report to U.S. Fish and Wildlife Service, Sacramento Field Office, 24 pp. + figs.

Knisley, C. B., and Hill, J. M. (1992). Habitat change from ecological and human impact influences tiger beetle species composition and abundance. Va. J. Sci. 43: 133-142.

Knisley, C. B., and Pearson, D. L. (1984). Biosystematics of larval tiger beetles of the Sulphur Springs Valley, Arizona. Descriptions of species and a review of larva characters for Cicindela (Coleoptera: Cicindelidae). Trans. Am. Entomol. Soc. 110: 465-551.

Knisley, C. B., and Schultz, T. D. (1997). The Biology of Tiger Beetles and a Guide to the Species of the South Atlantic States, Special Publication No. 5, Virginia Museum of Natural History, Martinsville, VA, 210 pp.

Larochelle, A., and Lariviere, M. C. (2001). Natural history of the tiger beetles of North America north of Mexico. Cicindela 33: 41-162.

Nagano, C. D. (1980). Population status of the tiger beetles of the genus Cicindela (Coleoptera: Cicindelidae) inhabiting the marine shoreline of southern California. Atala 8: $33-42$.

Pearson, D. L. (1988). Biology of tiger beetles. Annu. Rev. Entomol. 33: 123-147.

Pearson, D. L., and Vogler, A. P. (2001). Tiger Beetles: The Evolution, Ecology, and Diversity of the Cicindelids, Cornell University Press, Ithaca, New York, 333 pp.

Roos, T. (1957). Studies on upstream migration in adult stream-dwelling insects. Rep. Inst. Freshwater Res., Drottingholm 38: 167-192.
Schultz, T. D. (1988). Destructive effects of off-road vehicles on tiger beetle habitat in central Arizona. Cicindela 20: 25-29.

Shelford, V. E. (1908). Life histories and larval habits of the tiger beetles (Cicindelidae). J. Linnean Soc. Lond. - Zool. 30: 157-184

Shook, G. (1981). The status of the Columbia tiger beetle (Cicindela columbica Hatch) in Idaho. Pan-Pac. Entomol. 57: 359-363.

Stamatov, J. (1972). Cicindela dorsalis Say endangered on northern Atlantic coast. Cicindela 4: 78 .

Williams, D. D., and Williams, N. E. (1993). The upstream/downstream movement paradox of lotic invertebrates: Quantitative evidence from a Welsh mountain stream. Freshwater Biol. 30: 199-218.

Willis, H. L. (1967). Bionomics and zoogeography of the tiger beetles of saline habitats in the central United States (Coleoptera: Cicindelidae). Univ. Kans. Sci. Bull. 48: 145-313.

Wilson, D. A. (1970). Three subspecies of cicindelids threatened with extermination. Cicindela 2: $18-20$

Wilson, D. A. (1974). Survival of cicindelid larvae after flooding. Cicindela 6: 79-82.

Wilson, L. F. (1967). Distribution, abundance, and some habits of larvae of Cicindela hirticollis (Coleoptera: Cicindelidae) on a Lake Michigan Beach. Mich. Entomol. 1: 239- 244 .

Zerm, M., and Adis, J. (2002). Flight ability in nocturnal tiger beetles (Coleoptera: Carabidae: Cicindelinae) from central Amazonian floodplains. Coleopterists' Bull. 56: $491-500$.

Zerm, M., and Adis, J. (2004). Evidence for anaerobic metabolism in the larval tiger beetle Phaeoxantha klugii (Col. Cicindelidae) from a Central Amazonian floodplain (Brazil). Physiol. Entomol. 29: 483-488.

Zerm, M., Zinkler, D., and Adis, J. (2004). Oxygen uptake and local $\mathrm{PO}_{2}$ profiles in submerged larvae of Phaeoxantha klugii (Coleoptera: Cicindelidae), as well as their metabolic rate in air. Physiol. Biochem. Zool. 77: 378-389. 